\title{
ESTUDIO SOBRE LA METROLOGIA DE LA CECA ROMANA DE AUGUSTA EMERITA
}

\author{
POR \\ MIGUEL ÁNGEL CEBRIÁN SÁNCHEZ \\ Museo Cerralbo
}

\section{RESUMEN}

Se estudia la metrología en la ceca romana -imperial y provincial- de Augusta Emerita ${ }^{1}$. Dividimos el trabajo metrológico en dos grandes apartados, el primero analiza los pesos de las doce emisiones de la Mérida romana y el segundo pretende hacer una comparación con las otras cecas hispanas que, por su emisiones, están más próximas a las emeritenses. A esos dos apartados se añade una pequeña sección dedicada a la metalografía. A través de todo ello se demuestra que hubo dos sistemas metrológicos conviviendo, el republicano y el augústeo, emitiendose en Emerita y que el periodo de mayor auge de las emisiones incluye la etapa final del reinado de Augusto, post 2 a.C., y todo el reinado de Tiberio, lo que podría muy bien señalar el momento de apogeo y embellecimiento de la ciudad.

\section{SUMMARY}

Metrology analysis of the Roman currency in Augusta Emerita has allowed to distinguish two different metrological patterns. The former is a Roman imperial; the latter is a Hispanic one, this being used until the end of the Augustan reign. From B.C. 2 on, and throughout the Tiberian reign, coinage is only carried out following the imperial pattern. This happens at a time of high coinage production in Augusta Emerita, which might probably explain the city's urban development and embellishment heyday.

PALABRAS CLAVE: Augusto, Lusitania, Emerita, Reforma monetaria, metalografía, Pax Iulia, Ebora, Patricia, Traducta.

KEY WORDS: Lusitanian, Emerita, monetary reform, Metalografic, Pax Iulia, Ebora, Patricia, Traducta.

\section{INTRODUCCIÓN}

Uno de los mayores problemas que la numismática tiene hoy planteados es el cómo se efectuó el paso del sistema monetario republicano al imperial que Augusto crea posiblemente en el 23 a. C. y que permanecerá

\footnotetext{
1 Este trabajo, hoy actualizado, formó parte de la tesis doctoral titulada La ceca romana de Augusta Emerita, defendida en la Universidad de Córdoba en noviembre de 2003 y codirigida por los doctores María Paz García-Bellido y Carlos Márquez a quienes agradecemos su gran ayuda al respecto, como a la Dra. C. Blázquez los importantes comentarios al texto.
}

vigente hasta tiempos de Diocleciano. No sabemos cómo se realiza la transición de uno a otro, pero sí sabemos que desde luego ello no ocurre ni por decreto imperial, ni en todo el Imperio al mismo tiempo. Es pues de enorme interés el estudio metrológico de aquellas acuñaciones "transicionales" que están a caballo entre la tardía república y los inicios del Imperio, aquellas que tienen lugar entre el año 38 -año del gran reparto de las provincias en Brindisi (Dio Cassio 48, 28)-, el 23 en que suponemos que se hace la gran reforma monetaria imperial y el 2 a. C. en que podría estar ya generalizado, al menos en Hispania, el uso del nuevo patrón. Este interés no es sólo numismático, pues la reforma en que se llevan a término estas disposiciones imperiales nos proporciona una rica información sobre las redes del poder político y económico en las provincias y su real dependencia de Roma. Por ello, las acuñaciones de Perusa, Narbo, Arausio, Nemausus y en Hispania Celsa, todas ellas llevadas a cabo entre el 45 y el 27 a. C., han merecido una gran atención ${ }^{2}$, y por lo mismo, también pueden dar una gran información aquellas cecas que inauguran el nuevo sistema de manera progresiva, creo yo. Éste es el caso de la colonia Emerita, excepcional para la comprensión de este cambio pues en la ciudad no sólo se emitieron monedas imperiales (c. 24-22 a. C.) bajo el mandato de P. Carisio durante la segunda etapa de las guerras cántabras, sino también, monedas coloniales, desde su fundación (24-13 a. C.) y tras ello, (desde el 13-2 a. C.) como cabeza de la Lusitania. Excepto las imperiales, emitidas por P. Carisio, el resto parece haber seguido el patrón hispánico pre-reforma. Sólo tras el año 2 a. C. y durante todo el reinado de Tiberio, las emisiones emeritenses, ahora ya profusas, se acoplarán al sistema imperial. Después de Tiberio Emerita no acuñará más moneda.

La discusión metrológica que vamos a plantear aquí se ocasiona porque al final de la República la Lex Papiria (91 a. C.) había pretendido regular los pesos de la moneda de bronce, con una base teórica de $13.62^{3} \mathrm{~g}$ para los ases y de, aproximadamente, 7 y 3,5 g para los semises y cuadrantes. La ley no tuvo demasiada vigencia puesto que no se acuñó casi bronce en Roma desde

\footnotetext{
2 Amandry, M. (1986) pp. 21-33.

3 RRC, p. 611.
} 
esas fechas hasta tiempos de Augusto, por ello nos han quedado muy pocos ejemplares en los que podamos basarnos para constatar el uso y el efecto de la ley. En época augústea, más específicamente en el 23 a. C., se van a estructurar los pesos dentro de las profundas transformaciones que conllevó la reforma de Augusto de ese año ${ }^{4}$. Una gran gama de esas emisiones transicionales no sabemos encuadrarla ni en fechas ni en valores. Sus altos pesos, en algunos casos, podrían indicarnos que están siendo acuñados todavía según la ley Papiria ya devaluada, según patrones provinciales o que, por el contrario, estamos ya ante dupondios de nueva ley.

La reforma monetaria llevada a cabo por Augusto (lex Iulia) tuvo como base el patrón de 10,92 g es decir de $1 / 30$ de la libra romana ${ }^{5}$. Esta reforma también se realizó en las mismas fechas en Asia Menor (27-23 a. C.) pero no se incorporará en Roma hasta c. 17 a. C., siendo por tanto Emerita la primera colonia occidental en implantarla en sus emisiones. Uno o dos años antes esta metrología se había ya aplicado en el NO. en sus emisiones "militares" 6 que llamamos de "caetra", acuñadas posiblemente en Lucus Augusti. Ese nuevo sistema consistió en una escala de múltiplos y submúltiplos, cuyos valores más altos eran el sestercio en oricalco (cuatro ases), el dupondio en oricalco (dos ases), el as en cobre (unidad), y sus divisores, el semis en cobre (medio as) y el cuadrante en cobre (cuarto de as). Además el denario de plata (cuatro sestercios) y el áureo (25 denarios) ${ }^{7}$.

En Augusta Emerita no se acuñará moneda de oro que, sin embargo, sí se introducirá en el sistema augústeo, posiblemente porque la acuñación imperial emeritense es anterior a la creación del sistema. Sí se emitirá el oro en las colonias de Patricia y Celsa en los años 1816 a. C. Esta ausencia de oro en Emerita podría darnos, según García-Bellido, una fecha post quem 25 a. C. para una explotación imperial dirigida en los auraria de la Península ${ }^{8}$. Recordemos que el áureo se introduce en el sistema monetario tan solo dos años después de la fundación de Emerita y uno después de la partida de Augusto de Hispania, tras una estancia de tres años en ella, lo que podría indicar que su inauguración dependió de la explotación hispánica.

\footnotetext{
4 Sutherland (1984) 1-5; Burnett en RPC (1992) 26-37.

5 Las variaciones de los pesos en los ases hicieron pensar a Mattingly (BMC, p. XLVIII) y Sutherland (RIC, I, p. 3) en un peso base, para la unidad (as) de 10,92 y $11 \mathrm{~g}$; esta leve diferencia la consideramos por nuestra parte como insignificante. Para profundizar en el tema podemos utilizar el artículo de M. Amandry referido en la nota 2.

6 RPC, 1-4, DCyP II , p. 287.

7 Cf. DCyP, tomo I, pp. 90-92.

8 García-Bellido M. P. (2003) pp. 273-290.
}

Antes de entrar en la descripción de las series tenemos que tener en cuenta que las monedas de oro y plata se acuñaron al peso, es decir, el control en la cantidad de metal era mucho más rígido que en las emisiones de bronce, que se obtenían por lo general "al marco"; es decir de una libra se fabricaba un número de monedas determinado, siendo por ello la propia técnica de la acuñación empleada la que ocasionaba un peso variable. De hecho, hemos constatado en Emerita la utilización de la fundición de los flanes monetarios en rosario, lo que conlleva muy poca precisión en los pesos individuales ${ }^{9}$.

Otro de los problemas que pretendemos abordar en este análisis es la aparente diferencia de producción entre unas emisiones y otras, cuya escasez en algunos casos hemos podido vislumbrar por los hallazgos, pero en otros queda hoy sin posible explicación histórica.

\section{METROLOGÍA DE LA CECA EMERITENSE}

Las diferentes series se han estructurado en función de nuestro estudio de cuños a través del cual hemos podido diferenciar doce series, a las que hemos otorgado un número de orden que sigue una cronología relativa aunque, como veremos, también existen series paralelas, es decir coetáneas ${ }^{10}$. Algunos hitos nos permiten dar cronologías absolutas por lo que las emisiones emeritenses pueden ser fechadas con mayor precisión que la mayoría de las otras ciudades peninsulares.

Tanto la metrología como la iconografía han permitido diferenciar tres grandes periodos de la historia de la moneda en Emerita, periodos que se adaptan perfectamente a los hitos históricos de la ciudad que conocemos por las fuentes: $1^{\circ}$ ) Una etapa imperial, dependiente de la administración augústea, aplicada a asuntos militares, mientras la guerra dura, en la que la moneda ilustra temas de conquista (25-19 a.C?); $2^{\circ}$ ) su etapa colonial, con independencia de la administración imperial pero sin haberse convertido todavía en capital provincial, con temas cívico-fundacionales (23-13 a.C?) y $3^{\text {a }}$ ) su etapa provincial, como capital de Lusitania, provincia que se crea posiblemente en el año 13 a.C. a pesar de las palabras de Dion Cassio. Sus temas son ahora de menos en menos dirigidos a la ciudad y más a su papel de capital provincial. En esta etapa el mayor apogeo de la emisión de moneda se presencia tras el 2 a.C y durante el reinado de Tiberio.

\footnotetext{
9 DCyP, Tomo I, pp. 101-116.

${ }^{10}$ Esta estructuración en doce series también se fundamenta en motivos iconográficos y metrológicos analizados en la tesis doctoral inédita, mencionada en la nota 1 y que por la extensión del tema no incluimos en este trabajo. Estructuraciones similares para la ceca emeritense encontramos desde la obra de Vives (1926) y por último en la de García-Bellido y Blázquez (2001).
} 
Los parámetros metrológicos empleados en las distintas emisiones de la Mérida romana están en la fig. $1^{11}$ :

${ }^{11}$ Las monedas utilizadas en este estudio se corresponden con los fondos analizados en los monetarios del Museo Arqueológico Nacional, Museo Nacional de Arte Romano de Mérida, Museo Casa de la Moneda, Institución Valencia de don Juan, Museo Arqueológico y Etnológico de Córdoba, así como de fondos de colecciones privadas y subastas.

\subsection{Primer Período. Moneda ImPerial}

\section{Primera serie}

Las primeras monedas acuñadas por la ceca emeritense fueron emitidas bajo el control de P. Carisio, legado augustal para las campañas cántabras. Se trata de moneda de plata y a ello se debe el cuidado en el control de los pesos, mucho más rígido que en las piezas de

\begin{tabular}{|c|c|c|c|c|}
\hline & $\mathrm{N}^{\mathrm{i}}$ & $\mathrm{P} / \mathrm{M}$ & $\mathrm{P} / \mathrm{L}$ & $\mathrm{P} / \mathrm{P}$ \\
\hline $\begin{array}{l}1^{\mathrm{a}} \text { serie (imp) A } \\
\text { Quinario } \\
\text { Denario }\end{array}$ & $\begin{array}{l}85 \\
12\end{array}$ & $\begin{array}{l}\text { Ag. (85) } 1,68 \\
\text { Ag. (12) } 3,59\end{array}$ & $\begin{array}{l}1,45 \\
2,36\end{array}$ & $\begin{array}{l}1,96 \\
4,00\end{array}$ \\
\hline $\begin{array}{l}2^{\mathrm{a}} \text { serie (imp) A } \\
\text { Denario } \\
\text { Dupondio } \\
\text { As }\end{array}$ & $\begin{array}{r}81 \\
11 \\
205\end{array}$ & $\begin{array}{r}\text { Ag. (81) } 3,62 \\
\text { Oricalco. (11) } 9,46 \\
\text { Ae.(205) } 10,92\end{array}$ & $\begin{array}{l}2,82 \\
8,40 \\
6,00\end{array}$ & $\begin{array}{r}4,05 \\
10,85 \\
14,30\end{array}$ \\
\hline $\begin{array}{l}3^{\mathrm{a}} \text { serie }(\mathrm{Col}) \mathrm{A} \\
\text { As }\end{array}$ & 9 & Ae. (9) 13,50 & 8,56 & 20,40 \\
\hline $\begin{array}{l}4^{\mathrm{a}} \text { serie }(\mathrm{Col}) \mathrm{A} \\
\text { As } \\
\text { Semis } \\
\text { Cuadrante }\end{array}$ & $\begin{array}{r}17 \\
2 \\
2\end{array}$ & $\begin{array}{r}\text { Ae. (17) } 14,06 \\
\text { Ae. (2) } 6,96 \\
\text { Ae. (2) } 2,24\end{array}$ & $\begin{array}{r}10,09 \\
6,66 \\
2,08\end{array}$ & $\begin{array}{r}17,00 \\
7,27 \\
2,40\end{array}$ \\
\hline $\begin{array}{l}5^{\text {a }} \text { serie }(\mathrm{Col}) \mathrm{A} \\
\text { Dupondio } \\
\text { As }\end{array}$ & $\begin{array}{r}4 \\
67\end{array}$ & $\begin{array}{r}\text { Ae. (4) } 18,39 \\
\text { Ae. (67) } 10,05\end{array}$ & $\begin{array}{r}16,18 \\
7,33\end{array}$ & $\begin{array}{l}21,83 \\
15,42\end{array}$ \\
\hline $\begin{array}{l}6^{\text {a }} \text { serie (prov) A } \\
\text { Dupondio } \\
\text { As } \\
\text { Semis } \\
\text { Cuadrante }\end{array}$ & $\begin{array}{r}9 \\
44 \\
60 \\
11\end{array}$ & $\begin{array}{r}\text { Ae. (9) } 19,47 \\
\text { Ae. (44) } 11,03 \\
\text { Ae. (60) } 3,92 \\
\text { Ae. (11) } 2,68\end{array}$ & $\begin{array}{r}12,03 \\
7,30 \\
1,93 \\
1,93\end{array}$ & $\begin{array}{r}24,15 \\
15,50 \\
6,12 \\
3,35\end{array}$ \\
\hline $\begin{array}{l}7^{\mathrm{a}} \text { serie (prov) } \mathrm{T} \\
\text { Dupondio } \\
\text { As }\end{array}$ & $\begin{array}{l}20 \\
29\end{array}$ & $\begin{array}{r}\text { Ae. (20) } 21,20 \\
\text { Ae. (29) } 9,27\end{array}$ & $\begin{array}{r}15,23 \\
7,59\end{array}$ & $\begin{array}{l}25,23 \\
13,00\end{array}$ \\
\hline $\begin{array}{l}8^{\text {a }} \text { serie (prov) } \mathrm{T} \\
\text { Dupondio } \\
\text { As }\end{array}$ & $\begin{array}{r}69 \\
109\end{array}$ & $\begin{array}{r}\text { Ae. (69) } 18,02 \\
\text { Ae.(109) } 13,87\end{array}$ & $\begin{array}{r}13,34 \\
6,56\end{array}$ & $\begin{array}{l}29,33 \\
19,70\end{array}$ \\
\hline $\begin{array}{l}9^{\mathrm{a}} \text { serie (prov) } \mathrm{T} \\
\text { Dupondio } \\
\text { As } \\
\text { Semis }\end{array}$ & $\begin{array}{r}13 \\
80 \\
3\end{array}$ & $\begin{array}{r}\text { Ae. (13) } 22,30 \\
\text { Ae. (80) } 11,22 \\
\text { Ae. (3) } 6,34\end{array}$ & $\begin{array}{r}15,18 \\
5,32 \\
5,72\end{array}$ & $\begin{array}{r}31,46 \\
15,32 \\
6,81\end{array}$ \\
\hline $\begin{array}{l}10^{\mathrm{a}} \text { serie (prov) } \mathrm{T} \\
\text { Dupondio }\end{array}$ & 22 & Ae. (22) 22,11 & 16,23 & 28,96 \\
\hline $\begin{array}{l}11^{\mathrm{a}} \text { serie (prov) } \mathrm{T} \\
\text { As }\end{array}$ & 12 & Ae. (12) 11,87 & 10,34 & 13,37 \\
\hline $\begin{array}{l}12^{\mathrm{a}} \text { serie (prov) } \mathrm{T} \\
\text { Dupondio } \\
\text { As } \\
\text { Semis }\end{array}$ & $\begin{array}{r}33 \\
247 \\
8\end{array}$ & $\begin{array}{r}\text { Ae. (33) } 23,91 \\
\text { Ae. (247) } 10,80 \\
\text { Ae. (8) } 6,15\end{array}$ & $\begin{array}{r}14,45 \\
5,30 \\
4,08\end{array}$ & $\begin{array}{r}30,38 \\
17,66 \\
7,98\end{array}$ \\
\hline
\end{tabular}

Figura 1. Cuadro general de emisiones y pesos. 


\begin{tabular}{|c|c|c|c|c|}
\hline & $\mathrm{N}^{\mathrm{i}}$ & $\mathrm{P} / \mathrm{M}$ & $\mathrm{P} / \mathrm{L}$ & $\mathrm{P} / \mathrm{P}$ \\
\hline $\begin{array}{l}1^{\text {a }} \text { serie (imp) A } \\
\text { Quinario } \\
\text { Denario }\end{array}$ & $\begin{array}{l}85 \\
12\end{array}$ & Ag. (85) 1,68 & 1,45 & 4,00 \\
\hline
\end{tabular}

Figura 2. Metrología de la $1^{\text {a }}$ emisión emeritense.

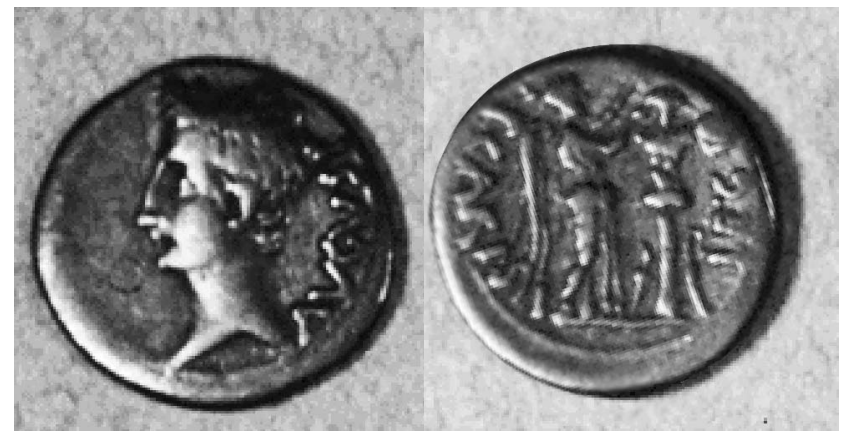

Figura 3. Quinario imperial de Emerita DCyP, 122, 1ª-1, 1:4.

bronce. Tradicionalmente estas emisiones se fechan en los primeros años de la fundación de la colonia (25-23 a. C.) y se componen de dos valores en plata: denarios y quinarios. Han sido de siempre calificadas como "moneda imperial", presentan una iconografía conmemorativa del triunfo sobre los cántabros y parecen emitidas inmediatamente después de la supuesta finalización de las guerras en el 25-24 a. C. que llevaron a Augusto a mandar cerrar prematuramente las puertas del templo de Jano (Dion Cassio 53,27,2), cuando en realidad la guerra no había terminado tal y como demostraría la necesidad de nuevas campañas bajo Agripa. Pero sabemos que con los emeriti de esta primera fase de la guerra se funda Augusta Emerita y se acuña ahora la plata para pagar estipendios y licenciamientos, en ella, puesto que en una de las series se inscribe EMERITA en el dintel de la puerta de la ciudad ${ }^{12}$. La dispersión de estas monedas documenta escasos hallazgos en el noroeste peninsular; sin embargo, García-Bellido ha atestiguado una frecuente presencia de esta plata emeritense en Germania superior/Raetia, llevándole a proponer que una legión entera parte hacia allí, y que con los nuevos licenciados se funda la colonia Augusta Emerita Raurica años después, emeriti de la legio V Alaudae que quisieron conmemorar, con el mismo nombre, su hermandad con los de Lusitania ${ }^{13}$. Sabemos que la guerra

12 Volk (1996) opina sin embargo que ninguna de estas monedas se acuñaron en Emerita y que este topónimo, en el dintel de la puerta de muchos denarios, es un homenaje a la colonia recién fundada. La propuesta no ha tenido ningún eco.

${ }^{13}$ García-Bellido, M.P. (2004) pp. 280-282. cántabra continúa, obligando a Agripa a una venida a Hispania en el año 19 a.C. fecha en que se puede dar por pacificada la región.

Quinario (RIC I 2 , 1a; DCyP, 122, $1^{\mathrm{a}} 1$ y 2) fig. $3^{14}$. Esta mitad del denario, siguiendo los pesos imperiales antes referidos, debe corresponderse con unos 1,921,82 g. Los cálculos arrojan una media de 1,68 y una oscilación que en ningún momento cae por debajo de 1,45 ni supera los 1,96 g. De nuevo nos encontramos con unos patrones un tanto inferiores de la media oficial, aunque habría que pensar que la oscilación hace que el quinario se encuentre en una banda regular y permitiría, por tanto, que pasara los controles habituales para este tipo de monedas; sobre todo, sí creemos que este valor fue el más utilizado por su menor liquidez, siendo más práctico a la hora de establecer intercambios cotidianos. En el gráfico, que se encuentra al final del estudio, se atestigua una concentración de pesos entre 1'5 y $2 \mathrm{~g}$, coincidiendo los pesos absolutos de casi todos los ejemplares con el peso medio establecido. La presencia de estos quinarios en Hispania está atestiguada especialmente en el NO y en la zona portuguesa aunque también en otros puntos de Levante y el sur ${ }^{15}$.

Denario (RIC I 2; DCyP, 122, $1^{\text {a }} 3$ ).- El denario tuvo un peso comprendido entre 3,85-3,65 $\mathrm{g}^{16}$ En la Mérida romana, Publio Carisio, como responsable de la emi-

\footnotetext{
${ }^{14}$ La bibliografia de referencía de las monedas se corresponde con la obra: García-Bellido, M. P.; Blázquez, C. (2001) Diccionario de cecas y pueblos hispánicos, tomo II, Madrid.

15 Blázquez, C. (1992) p. 284.

${ }^{16} \mathrm{RIC} \mathrm{I}^{2}$, p. 4.
} 


\begin{tabular}{|c|c|c|c|c|}
\hline & $\mathrm{N}^{\mathrm{i}}$ & $\mathrm{P} / \mathrm{M}$ & $\mathrm{P} / \mathrm{L}$ & $\mathrm{P} / \mathrm{P}$ \\
\hline $2^{\mathrm{a}}$ serie (imp) A & & & & \\
\hline Denario & 81 & Ag. (81) 3,62 & 2,82 & 4,05 \\
\hline Dupondio & 11 & Oricalco. (11) 9,46 & 8,40 & 10,85 \\
\hline & 205 & Ae.(205) 10,92 & 6,00 & 14,30 \\
\hline
\end{tabular}

Figura 4. Metrología de la $2^{\text {a }}$ emisión emeritense.

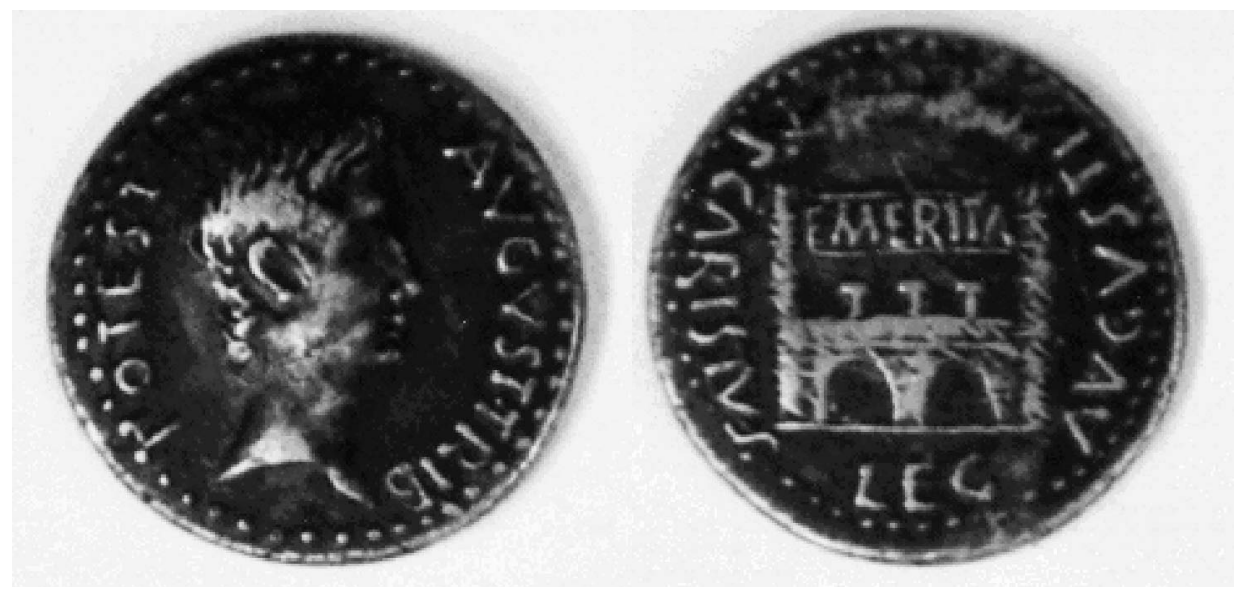

Figura 5. Dupondio imperial de Emerita DCyP, 123, 2ª $-13,1: 3$

sión, acuñó un denario con un peso medio de 3,59, levemente inferior a la banda antes indicada, pero que en todo caso no es sintomático, ya que los demás ejemplares analizados presentan una oscilación comprendida entre $\operatorname{los}$ 2,36-4,00 $\mathrm{g}$ indicando que se mantienen dentro de la calidad métrica que caracterizó las emisiones romanas en plata de época de Augusto.

\section{Segunda serie}

La segunda emisión de la ceca emeritense es posiblemente, coetánea a la primera y ambas de naturaleza imperial. También se acuñan denarios, y, además, se amplía la producción a valores en bronce (dupondios y ases), dando respuesta a las necesidades propias de una circulación bélica que precisa tanto de moneda fuerte para el pago final de soldadas como de moneda de menor valor, de tipo campamental. De hecho, estos bronces son firmados por Publio Carisio, como legado imperial y se encuentran con frecuencia en el NO. peninsular y en campamentos de Germania como en Novaesium y Abodiacum ${ }^{17}$.

\footnotetext{
${ }^{17}$ Uno de ellos ha aparecido en La Carisa (Asturias) en contexto militar y se podría fechar en c. 22 a.C. Jorge Camino en García-Bellido (2006), pp. 444 ss.
}

Denario (RIC I 4-10; DCyP, 123, 2a 4-9).- En este segundo momento se potencia la producción de denarios, probablemente en respuesta al escaso volumen de denarios de la primera serie y en compensación a la gran emisión de quinarios, amén de otras razones políticomilitares que se iban produciendo en la colonia recién fundada y que, posiblemente, coincidan con el momento de pagar a los soldados que parten hacia Raetia y a los eméritos que primigeniamente poblaron la ciudad y que forzaron la acuñación de este tipo de monedas. A tenor de los pesos vemos cómo, ahora, la media $(3,62$ g) encaja perfectamente en el intervalo oficial antes comentado y que la oscilación no supera el gramo en ningún caso. Los pesos medios, que hemos establecido, se corresponden con los pesos teóricos de la mayoría de las monedas utilizadas, manteniendo cada unidad una oscilación entre los 3,5-4 g de la escala.

Dupondio (RIC I, $11 \mathrm{a}-\mathrm{b}$; DCyP, 123, 2¹1) fig 5. Sobre este tipo de monedas se han defendido dos opiniones respecto al valor que corresponde. A. Vives en 1906 (140, 16-141, 1) las clasificó como ases y C. H. V. Sutherland en 1984, tras unos análisis metalográficos en los que se detectó el oricalco, las consideró como dupondios (RIC, $\left.\mathrm{I}^{2}, 11 \mathrm{a}-\mathrm{b}\right)$, interpretación, que indudablemente es la correcta. De los once ejemplares que hemos estudiado se deduce un peso medio de 9,46 g. La oscilación de sus pesos tampoco es muy grande (poco más de dos gramos) 8,40-10,85 g, hecho que creemos se debió a un 


\begin{tabular}{|l|r|r|r|r|}
\hline & $\mathrm{N}^{\mathrm{i}}$ & $\mathrm{P} / \mathrm{M}$ & $\mathrm{P} / \mathrm{L}$ & $\mathrm{P} / \mathrm{P}$ \\
\hline $\begin{array}{l}3^{\mathrm{a}} \text { serie (mun) A } \\
\text { As }\end{array}$ & 9 & Ae. (9) 13,50 & 8,56 & 20,40 \\
\hline
\end{tabular}

Figura 6. Metrología de la $3^{\text {a }}$ emisión emeritense.

mayor cuidado en la confección de los cospeles de estas piezas, cuya aleación de latón $(\mathrm{Cu}+\mathrm{Zn})$ era más costosa que las de bronce $(\mathrm{Cu}+\mathrm{Sn})$. Además, no debemos olvidar que estamos en una ceca imperial, habituada a la acuñación de plata y por ello con métodos mucho más precisos que los usados en las series coloniales emeritenses que a continuación comentaremos.

As ( RIC I, 13-25; DCyP, 123, 22 12 y 13).- En esta primera y voluminosa emisión de ases emeritenses encontramos una media de 10,92 g que encaja perfectamente con la nueva métrica impuesta por el príncipe Augusto y basada en una unidad de $11 \mathrm{~g}$. Sí podemos apreciar que el peso de estas monedas es más variable, con una fuerte oscilación comprendida entre los 6,00 y los 14,30 g. Las 205 monedas utilizadas para realizar este análisis concentran sus pesos entre los 8 a los $11 \mathrm{~g}$ por lo que el peso medio se mantiene cercano a los pesos teóricos de estas unidades.

\subsection{Segundo Período. Series Coloniales $\left(3^{\mathrm{a}}-5^{\mathrm{a}}\right.$ series $)$}

El segundo gran período de la ceca emeritense se corresponde con la producción de la propia colonia sin, al parecer, intervención imperial. Iconográficamente son las primeras emisiones con tipos relativos a la propia fundación de la ciudad (deidad mayor/yunta fundacional/insignias legionarias con los números de las unidades) y no a la conquista. Además de esta clara independencia iconográfica, la ceca utiliza ahora un patrón local, mucho más pesado que el imperial ${ }^{18}$. Desgraciadamente la localización de los hallazgos no justifica la producción de esta serie para un fin determinado. Pero en Oberhausen (Augusta Vindelicum), uno de los campamentos más tempranos de Germania superior, se ha hallado un semis emeritense, sin duda un recuerdo sentimental llevado desde Hispania a Germania por un soldado allí trasladado ${ }^{19}$. Ello nos indica que de alguna manera este bronce también tuvo relación con las tropas fundadoras $\mathrm{y}$, sobre todo, nos da una fecha muy temprana para esta emisión por el hallazgo de Oberhausen, cuya vida corre del 10/8 a.C. al 6/9 d.C., aunque es cierto que con habitación esporádica, no campamental, hasta el 16 d.C. El

\footnotetext{
${ }^{18}$ Cebrián, M. A. (2005) pp. 835-838.

19 García-Bellido (2004) p. 223
}

semis de Emerita aparece junto a un quinario y un denario también de Emerita de las $1^{\mathrm{a}}$ y $2^{\mathrm{a}}$ serie, y junto a un bronce de Celsa anterior al 13 a.C. ${ }^{20}$.

Tercera serie (Augusto, metrología hispana pre-reforma monetaria)

As (RPC 5; DCyP, 123, 3ª14).- Es el único valor acuñado y por lo que respecta a sus pesos destacamos una media alta, en torno a los 13,50 g y una gran oscilación métrica que abarca desde los 8,56 a los 20,40 g. Esta situación se encuentra en consonancia con las características propias de la emisión, ya que un cotejo de las piezas permite observar una falta de pericia técnica en la regularidad de los cuños realizados. Todo ello lo podríamos relacionar con la primera experiencia local que debió de tener la ceca de la Mérida romana respecto a los pesos, tenemos aquí documentada la supervivencia en época augústea del sistema republicano con un peso para la unidad de $13 \mathrm{~g}$ constatado en otras cecas peninsulares. Concluimos creyendo que esta serie pudo ser coetánea en el tiempo con las oficiales de P. Carisio (las dos anteriores), si bien, ahora, es la propia ciudad la responsable de su emisión. Es incluso posible que los talleres y los operarios dentro de la ciudad fueran distintos, dada la diferente calidad y metrología de las emisiones.

Cuarta serie (Augusto, metrología hispana pre-reforma monetaria)

Estas monedas iconográficamente muestran una continuidad respecto a la anterior emisión, ya que hacen alusión a ritos locales por lo que debemos entenderlas próximas en el tiempo, cuando no cronológicamente paralelas a las dos series anteriores. Frente a la anterior serie, que solamente acuñó ases, ésta además cuenta con divisores semises y cuadrantes que paliaron la carencia de monedas de poco valor en la propia ciudad y en sus inmediaciones. Motivo éste muy propio de las emisiones coloniales emeritenses. Los escasos hallazgos, sólo un testimonio en Castrejón de Capote (Badajoz) y el de Oberhausen arriba mencionado, no permite evaluar la difusión de la serie que, parece muy vinculada al propio territorio de Emerita ${ }^{21}$.

\footnotetext{
${ }^{20}$ García-Bellido (2004) pp. 223-226.

${ }^{21}$ Blázquez (1992) pp. 118-126.
} 


\begin{tabular}{|c|c|c|c|c|}
\hline & $\mathrm{N}^{\mathrm{i}}$ & $\mathrm{P} / \mathrm{M}$ & $\mathrm{P} / \mathrm{L}$ & $\mathrm{P} / \mathrm{P}$ \\
\hline $4^{\mathrm{a}}$ serie (mun) A & & & & \\
\hline & 17 & Ae. (17) 14,06 & 10,09 & 17,00 \\
\hline Semis & 2 & Ae. (2) 6,96 & 6,66 & 7,27 \\
\hline Cuadrante & 2 & Ae. (2) 2,24 & 2,08 & 2,40 \\
\hline
\end{tabular}

Figura 7. Metrología de la $4^{\mathrm{a}}$ emisión emeritense.

\begin{tabular}{|c|c|c|c|c|}
\hline & $\mathrm{N}^{\mathrm{i}}$ & $\mathrm{P} / \mathrm{M}$ & $\mathrm{P} / \mathrm{L}$ & $\mathrm{P} / \mathrm{P}$ \\
\hline $\begin{array}{l}5^{\text {a }} \text { serie (mun) A } \\
\text { Dupondio } \\
\text { As }\end{array}$ & $\begin{array}{r}4 \\
67\end{array}$ & $\begin{array}{r}\text { Ae. (4) } 18,39 \\
\text { Ae. (67) } 10,05\end{array}$ & $\begin{array}{r}16,18 \\
7,33\end{array}$ & $\begin{array}{l}21,83 \\
15,42\end{array}$ \\
\hline
\end{tabular}

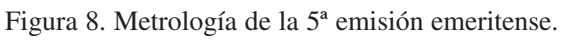

As (RPC 6-7; DCyP, 124, 4 15 ).- Las unidades que se acuñaron en este momento mantienen unos valores medios un tanto altos $(14,06 \mathrm{~g})$ para estas denominaciones, si los referimos a los patrones establecidos en el principado de Augusto y que ya en la segunda emisión de esta ceca fueron utilizados, por lo que se puede plantear la perduración de la métrica pre-reforma en época augústea. M. Amandry ha encontrado en Galia unos valores altos y similares a los que aquí mostramos, interpretándolos como emisiones pre-reforma ${ }^{22}$. Entre la moneda más ligera $(10,09)$ y la más pesada $(17,00)$ existe una oscilación de casi $7 \mathrm{~g}$, y esta sensible diferencia la achacamos a la realización de cospeles irregulares, fabricados por el sistema de fundición con técnica en rosario ${ }^{23}$. El peso medio fijado en esta emisión no se corresponde con los pesos reales. Además, nos enfrentamos al problema de contar con pocos ejemplares para elaborar un gráfico fiable que precisara más los matices evolutivos de los avatares en esta producción. Los análisis metalográficos de tres ejemplares RPC 6 permiten observar una notable variabilidad en la aleación: así el cobre oscila entre $96^{\prime} 6$ y $88^{\prime} 5 \%$ y lo mismo sucede con el estaño que presenta cifras entre $8^{\prime} 6$ y $2^{\prime} 96 \%$, mientras que el plomo en esta serie no supera el $1 \%$ en ningún caso ${ }^{24}$.

Semis (RPC 8; DCyP, 124, 4ª).- Los primeros divisores acuñados por la ceca emeritense tienen una métrica en consonancia con la mitad de un as de $11 \mathrm{~g}$. El peso medio es de 6,96 g y la variación no llega a un gramo $(6,66-7,27)$. Estas cifras parecen lo bastante significativas para pensar en unos pesos cuidados, sobre todo en relación con otros valores, que permitiesen una

\footnotetext{
22 Amandry (1986) pp. 22 y ss.

23 Una explicación amplia sobre el tema la tenemos en: García-Bellido (1992) pp. 9-50.

${ }^{24}$ Parrado (1998) p. 107 no 409; RPC, 6.
}

confianza entre los usuarios de estas nuevas denominaciones en un ámbito local. Sólo contamos con cuatro ejemplares (con un solo cuño de anverso y dos de reverso atestiguados) de esta emisión que no nos permiten precisar matices y evoluciones dentro de la propia serie. Creemos que se trata de la misma, pese a la diferencia de sus pesos, por la continuación de los tipos de anverso, una divinidad arrojando agua por la boca.

Cuadrante (RPC 9; DCyP, 124, $4^{\mathrm{a}} 17$ ).- Estos primeros cuartos de as acuñados en Augusta Emerita tienen un peso medio de $2,24 \mathrm{~g}$, un tanto bajo sobre todo si se compara con la precisión mantenida en los semises. Sin embargo, hay que tener en cuenta que los escasos ejemplares constatados, solamente dos salidos de la misma pareja de cuños, no nos permiten poder profundizar más en su análisis metrológico.

Quinta serie (Augusto, metrología hispana pre-reforma monetaria)

En este momento la ciudad continúa haciendo referencia en su producción monetaria a la reciente fundación y por ello ilustra elementos locales tan destacados como el río y el sistema poliorcético de la ciudad. Esta serie de carácter local se clasificaba, tradicionalmente, entre las de época augústea de la ciudad ${ }^{25}$. Ahora, podemos precisar que se sitúa entre las series locales paralelas a ellas y anteriores al 2 a. C. La mejor justificación de la producción de dupondios, en esta emisión, es la expuesta por M. Amandry que considera que este valor se volvió a acuñar por una cuestión de ahorro de los costes de producción, aunque no se contaba con un modelo inmediato, su empleo se ha constatado en todo occidente, sobre todo en la Galia e Hispania ${ }^{26}$. La circulación de

\footnotetext{
25 Vives (1926), Tomo IV, p. 63.

${ }^{26}$ Amandry (1986) p. 34.
} 

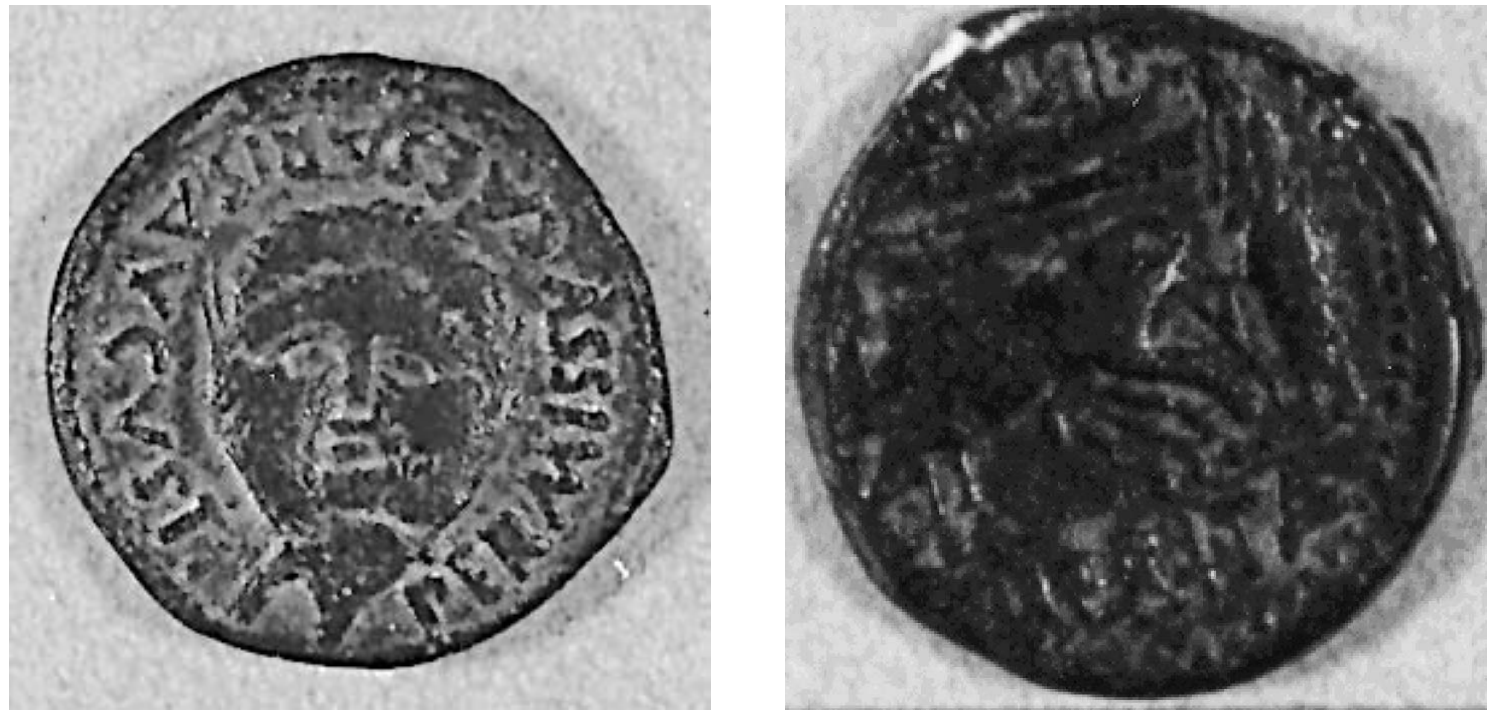

Figura 9. As local de Emerita DCyP, 124, 5ª-19, 1:2.

estas monedas demuestra su predominio en el territorio lusitano (Montemolín, Ribera del Fresno y Ruecas) pero también las encontramos en el noroeste: Oporto, Castelo; Levante: Camporrobles y en la Bética: Montefrío. Es posible que la mayor dispersión geográfica de estas monedas sea debida a los militares tras las campañas.

Dupondio (RPC 10; DCyP, 124, 5 18 ).- En indudable relación con el ahorro de los costes, antes comentado, están los pesos bajos de los duplos emeritenses, debido a que ahora se realizan en oricalco, con una media de $18,39 \mathrm{~g}$, y una variación de unos $5 \mathrm{~g}(16,18$ $21,83)$. Estas deficiencias técnicas y métricas constituyen una muestra del bajo nivel técnico de la ceca colonial. Respecto a la evolución de los pesos, sólo disponemos de cuatro ejemplares por lo que no podemos precisar cambios o grupos formados a partir de sus pesos.

As (RPC 11; DCyP, 124, 5 19 ) fig. 9.- En este caso la elevada cantidad de monedas examinadas, cerca de 70 , permite un margen de confianza. El peso medio obtenido de ellos es de 10,05 g y su variación es de $8 \mathrm{~g}$ $(7,33-15,42)$. Estos datos hacen sospechar un sistema de producción más preocupado por emitir un alto número de monedas que por mantener un peso uniforme. En ello influyó la técnica de fundición en árbol o rosario, de la que todavía reconocemos los puntos de unión debidamente cortados que se utilizó para la acuñación y en la que la imprecisión del vertido de metal origina una sensible oscilación de los pesos. La media de 11 g está en consonancia con las establecidas en época augústea por lo que podría distar poco tiempo de las primeras series imperiales. Los análisis metalográficos de estos ases reflejan que la correlación entre cobre, plomo y estaño no resulta en absoluto homogénea si no que los porcen- tajes de estos elementos varían notablemente ${ }^{27}$. S. Parrado observa la fuerte variabilidad existente en las emisiones augústeas emeritenses frente a la mayor homogeneidad en las aleaciones tiberianas ${ }^{28}$. Si comparamos los datos de los seis ejemplares analizados se observa que el cobre llega a alcanzar un $95^{\prime} 50 \%$ pero en otros casos desciende hasta el 81'50 \%. Algo similar sucede con el plomo que en algunas piezas llega al 11'65 \% mientras en otras no alcanza el $1 \%$. También el estaño oscila entre $8 ` 26 \%$ y el $0^{\prime} 05 \%$ aunque en la mayoría de los ases anda cerca del $5 \%$.

\subsection{TERCER PERÍOdo. \\ Series Provinciales ( $6^{\mathrm{a}}-12^{\mathrm{a}}$ series $)$.}

Se inicia ahora lo que hemos definido como período provincial de la ceca, cuando Emerita asume el papel de capital provincial y cambia tanto su iconografía como la proporción de emisiones, más voluminosas y completas en valores que las anteriores. El apogeo de esta representatividad tendrá lugar con Tiberio. Se trata de la toma de conciencia por la ciudad de su papel de capital provincial y nos encontramos por primera vez en moneda local con retratos del príncipe Augusto y con ejemplos palmarios, que vuelven a los tipos iniciales, de la puerta y su recinto murario, la fundación colonial, las legiones fundadoras y la religión ${ }^{29}$. Esta emisión cuenta con

\footnotetext{
27 Parrado (1998) p. 107 n 401-404 y RPC 11.

28 Parrado (1998) p. 106

${ }^{29}$ Cebrián (2005).
} 


\begin{tabular}{|c|c|c|c|c|}
\hline & $\mathrm{N}^{\mathrm{i}}$ & $\mathrm{P} / \mathrm{M}$ & $\mathrm{P} / \mathrm{L}$ & $\mathrm{P} / \mathrm{P}$ \\
\hline $6^{\mathrm{a}}$ serie (pro) A & & & & \\
\hline Dupondio & 9 & Ae. (9) 19,47 & 12,03 & 24,15 \\
\hline & 44 & Ae. (44) 11,03 & 7,30 & 15,50 \\
\hline Semis & 60 & Ae. (60) 3,92 & 1,93 & 6,12 \\
\hline Cuadrante & 11 & Ae. (11) 2,68 & 1,93 & 3,35 \\
\hline
\end{tabular}
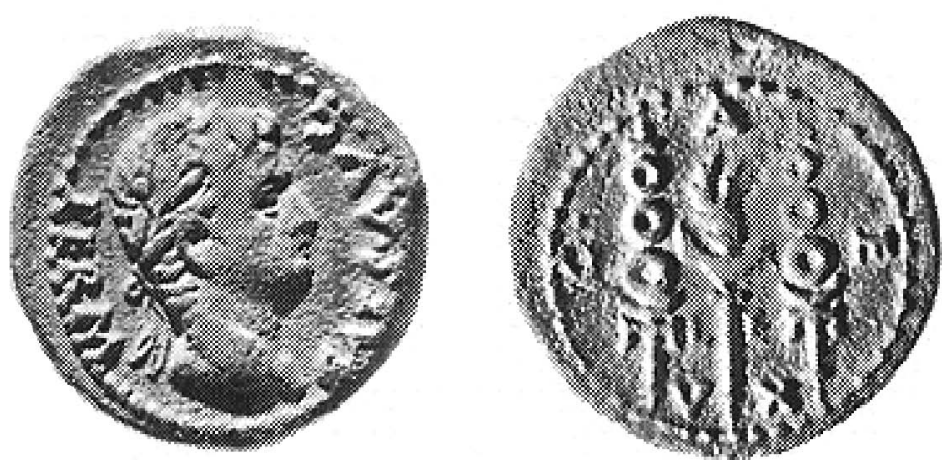

Figura 11. Semis provincial de Emerita DCyP, 125, 6ª -24, 1:2.

el más amplio número de valores acuñado, en esta ceca, parangonable sólo a otras capitales hispanas, como es el caso de Patricia en la Bética.

\section{Sexta Serie (Augusto, metrología provincial post-reforma)}

Es la primera vez, a excepción de la acuñación imperial inicial, que se implanta la metrología augústea en Emerita. Esta producción cuenta con la inclusión del título pater patriae en la leyenda de anverso, por lo que se fecha post 2 a. C. Sus hallazgos predominan en la zona occidental peninsular (Pontevedra, Cogolludo, Faro en el Algarbe portugués, Torres Vedras, en la desembocadura del Tajo), por lo que las necesidades que suplieron serían predominantemente de carácter provincial.

Dupondio (RPC 12; DCyP, 124, 620).- Encontramos en este momento una irregularidad métrica en los dupondios de la emisión que ofrecen un peso medio de 19,97 g pero con una marcada oscilación que supera los doce gramos $(12,03-24,15)$. Habría que conocer la composición metalográfica para ver si la diferencia de peso se basa en la diferencia de aleación metálica, es decir que sea o no oricalco y cobre. Hasta el momento esta es la variación mayor de pesos constatada en una misma emisión ${ }^{30}$. El gráfico correspon-

\footnotetext{
${ }^{30}$ Por el momento sólo conocemos el análisis de un ejemplar publicado en RPC 12, cuya ratio en la aleación ternaria es la siguiente: $\mathrm{Cu} 92^{\prime} 50, \mathrm{~Pb} 0^{\prime} 28, \mathrm{Sn} 5^{\prime} 81$. El peso de este bronce es de $16^{\prime} 10 \mathrm{~g}$.
}

diente no nos aclara nada al respecto, ya que contamos con escasos ejemplares para realizar un análisis en profundidad.

As (RPC 13; DCyP, 124, 621).- En los ases emeritenses de esta sexta emisión hemos podido atestiguar un peso medio que corresponde con una unidad de $11^{\prime} 00 \mathrm{~g}$, pero también con una marcada oscilación de 8,20 g, entre los pesos más extremos $(7,30-15,40)$. Esta disposición estaría dentro de la norma que ya se ha atestiguado en anteriores emisiones (unidades de la quinta y cuarta emisión).

Semis (RPC 14-18; DCyP, 124, 5²2-26) fig. 11.- Las mitades de esta serie se caracterizan por un peso medio de casi cuatro gramos $(3,92)$, sus pesos más bajos se encuentran en una moneda de $1,93 \mathrm{~g}$ y el ejemplar más pesado unos 6,12 g; la amplitud es por tanto de 4,19 g. Esto evidencia una vez más el poco cuidado que se tenía a la hora de confeccionar los cospeles de las monedas de escaso valor. Ocurre algo similar en los valores del semis y cuadrante de la serie que hemos denominado cuarta (RPC 8 y 9).

Cuadrante (RPC 19; DCyP, 125, 6 27).- En esta segunda, y última, emisión de cuadrantes en la ceca emeritense encontramos unos pesos medios de 2,68 g, bastante próximos a un cuarto de una unidad de once gramos. Las oscilaciones de pesos, en estos valores bajos de la escala, suelen variar tanto como en las unidades y duplos. En este caso encontramos un ejemplar de $1,93 \mathrm{~g}$ y otro de $3,35 \mathrm{~g}$, es decir una diferencia de $1,42 \mathrm{~g}$. 


\begin{tabular}{|c|c|c|c|c|}
\hline & $\mathrm{N}^{\mathrm{i}}$ & $\mathrm{P} / \mathrm{M}$ & $\mathrm{P} / \mathrm{L}$ & $\mathrm{P} / \mathrm{P}$ \\
\hline $7^{\mathrm{a}}$ serie (pro) $\mathrm{T}$ & & & & \\
\hline Dupondio & 20 & Ae. (20) 21,20 & 15,23 & 25,23 \\
\hline As & 29 & Ae. (29) 9,27 & 7,59 & 13,00 \\
\hline
\end{tabular}

Figura 12. Metrología de la $7^{\mathrm{a}}$ emisión emeritense.

\begin{tabular}{|c|c|c|c|c|}
\hline & $\mathrm{N}^{\mathrm{i}}$ & $\mathrm{P} / \mathrm{M}$ & $\mathrm{P} / \mathrm{L}$ & $\mathrm{P} / \mathrm{P}$ \\
\hline $8^{\mathrm{a}}$ serie (pro) $\mathrm{T}$ & & & & \\
\hline Dupondio & 69 & Ae. (69) 18,02 & 13,34 & 29,33 \\
\hline As & 109 & Ae.(109) 13,87 & 6,56 & 19,70 \\
\hline
\end{tabular}

Figura 13. Metrología de la $8^{a}$ emisión emeritense.

\section{Séptima serie (Tiberio)}

La emisión, de carácter provincial, de ases y duplos de este momento tiene como referente los dos tipos más significativos de la ceca: la cabeza del príncipe y la puerta de la ciudad y entrarían dentro de las series dedicadas, en época tiberiana, a la divinización de Augusto $^{31}$.

Dupondio (RPC 20-21; DCyP, 125, 7 28).- Los duplos de esta serie tienen un peso medio de 21,20 g y una amplitud métrica de diez gramos exactos $(15,23$ $25,23 \mathrm{~g}$ ). Estas características también las encontramos en otras series de dupondios, por ejemplo en la emisión anterior los pesos son similares y se observa una amplia oscilación en las monedas; pero no ocurre lo mismo en la quinta donde la menor variabilidad de los pesos pudo responder a un mayor cuidado en la producción de cospeles, hecho éste constatado en otras cecas hispanas que acuñaron bajo el gobierno de Tiberio ${ }^{32}$. Los gráficos muestran la amplitud antes comentada y, además, hemos creído poder diferenciar tres grupos: uno con pesos altos (25-23 g), otro comprendido entre los 21-19 g y un último de pesos bajos (15-17 g) que pueden corresponder a diferencias cronológicas entre ellos, o diferentes composiciones metálicas ${ }^{33}$. No hay hallazgos de estas monedas que puedan ayudarnos a esclarecer su finalidad.

31 Cebrián (2005)

${ }^{32}$ Llorens (1987) pp. 52 y 55. Del mismo modo en: RIC, I², pág. 90 se puede ver una comparación entre pesos augústeos y tiberianos, donde los segundos dan unos valores medios más altos y homogéneos.

33 De momento, sólo contamos con el análisis de un ejemplar del museo de Zamora Parrado (1998) p. 107 n 414 y los dos recogidos en RPC 21. A pesar de ser sólo tres bronces la variabilidad en las proporciones de la aleación utilizada es notable, sobre todo en $\mathrm{Cu}, \mathrm{Pb}$ y $\mathrm{Sn}$.
As (RPC 22; DCyP, 125, 7²9).- La media que tenemos en estos ases $(9,27)$ es un tanto baja para el patrón estipulado en época de Augusto. Los ejemplares estudiados no son muy numerosos (29 ases) para poder establecer unas conclusiones fiables pero podemos aportar el dato de una moneda más ligera con 7,59 g y de la más pesada que tiene 13,00 g. Estos valores están muy próximos a las unidades de la segunda emisión. La disposición del gráfico se distribuye uniformemente sin que podamos precisar concentraciones que coincidan con el peso medio antes comentado. Sin duda, esta fuerte diferencia petrológica está vinculada con la gran variabilidad que revelan los análisis metalográficos de estos ases. Se trata siempre de aleaciones ternarias pero la ratio entre $\mathrm{Cu}, \mathrm{Pb}$ y $\mathrm{Sn}$ no resulta en absoluto homogénea ${ }^{34}$. Respecto a su circulación no hemos podido encontrar hallazgos constatados que nos apoyen.

\section{Octava serie (Tiberio)}

Este momento productivo provincial se caracterizó por la acuñación de abundantes duplos y unidades con tipos alusivos a la ciudad y al culto imperial. La intención iconográfica es la de resaltar la adoración al emperador. Los hallazgos de estas monedas se producen en la actual región de Extremadura y el oeste de Castilla La Mancha (Alcantara y La Bienvenida), aunque también se testimonian en Andalucía (Nueva Carteya, provincia de Córdoba y provincia de Cádiz), lo que parece indicarnos que su objetivo fue complementar el circulante provincial ${ }^{35}$.

\footnotetext{
${ }^{34}$ Las piezas analizadas por Parrado (1998) pp. 107-108 números 415-417 y en RPC 22 revelan oscilaciones en el $\mathrm{Cu}$ entre 82 y 97’36 \% y por ejemplo en el $\mathrm{Pb}$ entre $0^{\prime} 24$ y $10^{\prime} 42 \%$.

35 Blázquez (1992) pp. 250-253.
} 


\begin{tabular}{|c|c|c|c|c|}
\hline & $\mathrm{N}^{\mathrm{i}}$ & $\mathrm{P} / \mathrm{M}$ & $\mathrm{P} / \mathrm{L}$ & $\mathrm{P} / \mathrm{P}$ \\
\hline $9^{a}$ serie (pro) $\mathrm{T}$ & & & & \\
\hline Dupondio & 13 & Ae. (13) 22,30 & 15,18 & 31,46 \\
\hline & 80 & Ae. (80) 11,22 & 5,32 & 15,32 \\
\hline Semis & 3 & Ae. (3) 6,34 & 5,72 & 6,81 \\
\hline
\end{tabular}

Figura 14. Metrología de la $9^{a}$ emisión emeritense.

Dupondio (RPC 23-25; DCyP, 125, 8a30).- Los sesenta y nueve ejemplares recopilados permiten los siguientes comentarios: el ejemplar más ligero tiene 13,34 g y el más pesado 29,33 g; por tanto la oscilación es de 15,99 g. De nuevo, nos encontramos con una dinámica que parece ser común en la ceca emeritense: el poco interés en regular unos pesos próximos a los oficiales, lo que hace suponer que lo importante es fabricar un determinado número de monedas con una cierta cantidad de metal. Si nos fijamos en la media sí encontramos un peso próximo al teórico para estos valores. En este caso contamos con monedas suficientes para poder analizar el comportamiento de los pesos en el gráfico que ratifica cómo se distribuyen uniformemente a lo largo de la oscilación sin que podamos precisar concentraciones.

As (RPC 26-29; DCyP, 125, 831-32).- Contamos con más de 100 ejemplares de esta emisión, que tienen un peso medio de unos $13,87 \mathrm{~g}$ y una variabilidad de 13,04 g (6,56-19,70) que llegan prácticamente a duplicar el peso que realmente les corresponde. Estos resultados están muy próximos a los de las emisiones anteriores. El gráfico de este valor de la $8^{\mathrm{a}}$ emisión se distribuye a lo largo de la oscilación manteniendo una concentración en torno a los $12 \mathrm{~g}$, un poco alejado del peso medio establecido. Los análisis metalográficos de ases RPC 26 se mantienen en una línea similar a las emisiones anteriores: el cobre juega un papel importante pero no con una cantidad estable y algo similar sucede con el estaño $^{36}$.

\section{Novena serie (Tiberio)}

La última serie dedicada a la divinización de Augusto se compone de duplos, unidades y mitades. La inclusión de las iniciales de la ciudad Colonia Augusta Emerita en la leyenda la diferencian de las dos series anteriores. Su producción podría haber sido paralela a ellas o consecutiva, pues no disponemos de datos para establecer una cronología relativa dentro de los primeros años del principado de Tiberio.

\footnotetext{
${ }^{36}$ Parrado (1998) p. 108 números 418-421. En estos ases el cu oscila entre el 93’9 \% y 78’96 \% y el $\mathrm{Sn}$ alcanza $9^{\prime} 29 \%$ pero llega a descender hasta 3’14\%.
}

Dupondio (RPC 30; DCyP, 126, 9a34).- Los trece ejemplares que hemos podido recopilar arrojan un peso medio de 22,30 g y una amplitud métrica de $16,18 \mathrm{~g}$ $(15,18-31,46)$, es decir, continúan la tónica marcada por las anteriores emisiones de grandes diferencias en una misma serie (duplos de la quinta y sexta). En el gráfico correspondiente no podemos precisar nada ya que son pocos los ejemplares y se encuentran distribuidos a lo largo de la oscilación. No tenemos constancia de hallazgos.

As (RPC 31-36; DCyP, 126, 9³5-38).- Los ochenta ases de esta serie cuentan con un peso medio de $11,22 \mathrm{~g}$ y unos valores extremos de 5,32 y 15,32 (10 g de variación). De nuevo, vemos una media ajustada a los pesos oficiales augústeos, pero una variación amplia en pesos absolutos, al igual que en anteriores emisiones. El gráfico correspondiente tiene una concentración de valores en torno a los diez-once gramos que coincide con el peso medio de estas monedas. Contamos con análisis de estas monedas en el RPC y en un trabajo de S. Parrado en el que el cobre es el metal preponderante con más del $90 \%$ de su composición ${ }^{37}$.

Semis (Semis 37; DCyP, 126, 9a39).- Pocos son los ejemplares que hemos podido atestiguar de esta emisión (tres ejemplares), lo que no nos permite establecer unos valores métricos lo suficientemente fiables. El peso medio se establece en 6,34 g y las variaciones extremas son de 5,72-6,81. Estas medidas están próximas a anteriores emisiones de mitades, sobre todo de la cuarta emisión. El gráfico no aclara nada respecto de la evolución.

\section{Décima serie (Tiberio)}

Abandonamos las emisiones dedicadas a la deificación de Augusto en el gobierno de Tiberio para entrar en una serie de duplos donde se hace propaganda expresa de Livia, esposa de Augusto y madre de Tiberio ${ }^{38}$. La situamos en el tiempo entre los años 18-19 d. C., por la alusión a la recuperación de la emperatriz e inmediatamente hecha tras las tres series anteriores dedicadas a la divinización. Esta representación de Livia no es exclusiva de la ceca emeritense, también la encontramos en

\footnotetext{
${ }^{37}$ RPC I, 69 y ss.; Parrado (1998) p. 107 n 410-412.

${ }^{38}$ Cebrián (2005).
} 


\begin{tabular}{|l|r|r|r|r|}
\hline & $\mathrm{N}^{\mathrm{i}}$ & $\mathrm{P} / \mathrm{M}$ & $\mathrm{P} / \mathrm{L}$ & $\mathrm{P} / \mathrm{P}$ \\
\hline $\begin{array}{l}10^{\mathrm{a}} \text { serie (pro) } \mathrm{T} \\
\text { Dupondio }\end{array}$ & & Ae. (22) 22,11 & 16,23 & 28,96 \\
\hline
\end{tabular}

Figura 15. Metrología de la $10^{\mathrm{a}}$ emisión emeritense.

\begin{tabular}{|l|r|r|r|r|}
\hline & $\mathrm{N}^{\mathrm{i}}$ & $\mathrm{P} / \mathrm{M}$ & $\mathrm{P} / \mathrm{L}$ & $\mathrm{P} / \mathrm{P}$ \\
\hline $\begin{array}{l}11^{\mathrm{a}} \text { serie (pro) } \mathrm{T} \\
\text { As }\end{array}$ & & & & \\
\end{tabular}

Figura 16. Metrología de la $11^{\mathrm{a}}$ emisión emeritense

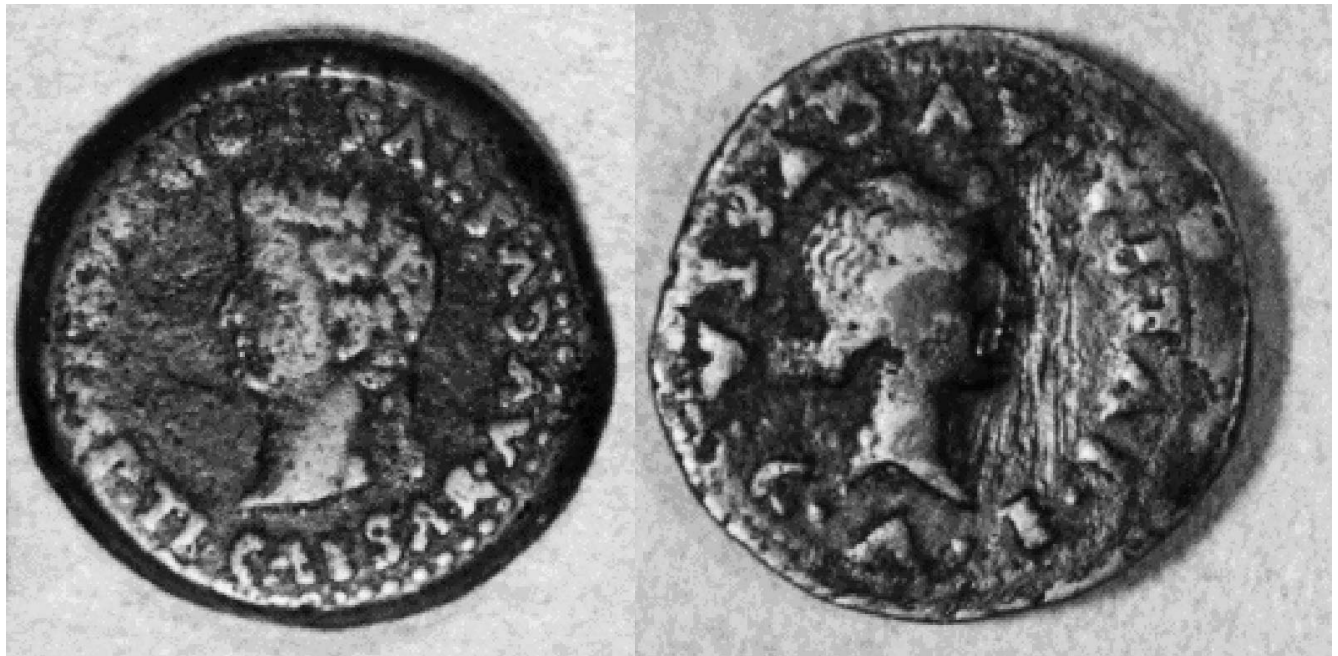

Figura 17. As Tiberio provincial de Emerita DCyP, 126, 11ª-42, 1:2.

Caesaraugusta (RPC 341) e Italica (RPC 66-67). En las tres cecas sobre acuñaciones tiberianas y con la misma iconográfia: entronizada y con cetro.

Dupondio (RPC 38-39; DCyP, 126, 10²40-41).- Los dupondios de esta emisión tienen unos pesos que oscilan entre los 16,23 y 28,96 g de donde deducimos un amplio intervalo métrico de $12,73 \mathrm{~g}$. Sin embargo, su peso medio $22,11 \mathrm{~g}$ se ajusta a los parámetros normales.

\section{Undécima serie (Tiberio)}

Esta penúltima serie la componen solamente ases dedicados a la memoria de Livia, representada de perfil en reverso, mientras que en el anverso aparece el retrato de su hijo Tiberio, tipo por primera vez presente en la ceca de la Mérida romana. Esta serie es paralela en el tiempo a la doceava con la que comparte un cuño de anverso. No consideramos que estas monedas formen parte de la serie siguiente por los tipos de reverso -retrato de Julia- los cuales son una excepción que nada tiene que ver con los tipos empleados posteriormente (puerta, altar y templo).

As (RPC 40; DCyP, 126, $11^{\mathrm{a}} 42$, fig. 17.- La docena de ases recopilados proporcionan uno peso medio de $11,87 \mathrm{~g}$, por lo que continuamos con una metrología próxima a la de las series anteriores. También vale la pena señalar que los $3 \mathrm{~g}$ de intérvalo (10,34-13,37 g), constituyen un claro indicativo del cuidado métrico en época tiberiana, algo que no se había producido bajo Augusto.

\section{Decimosegunda serie (Tiberio)}

La última de las acuñaciones provinciales de Emerita del principado de Tiberio, quien ocupa el tipo de anverso mientras en los reversos se mantiene los anteriores motivos (puerta, altar y templo). Estos son utilizados ahora para expresar una continuidad que parece también reflejarse en los pesos numismáticos. Los valores que cierran la producción de la ceca, dupondios, 


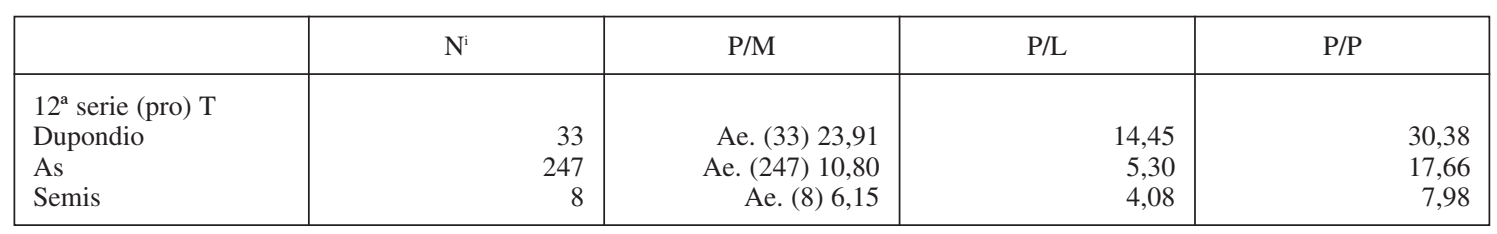

Figura 18. Metrología de la $12^{\mathrm{a}}$ emisión emeritense.

\begin{tabular}{|l|c|c|c|c|c|c|}
\hline Valor/Ceca-serie & Acci $\left(1^{\mathrm{a}}\right.$ y $\left.2^{\mathrm{a}}\right)$ & Traducta $\left(1^{\mathrm{a}}\right)$ & Patricia $\left(1^{\mathrm{a}}\right)$ & Pax Ivlia $\left(1^{\mathrm{a}}\right.$ y $\left.2^{\mathrm{a}}\right)$ & Ebora $\left(1^{\mathrm{a}}\right)$ & Emerita $\left(6^{\mathrm{a}}\right)$ \\
\hline Dupondio & & 19,76 & 19,44 & & 19,75 & 19,47 \\
\hline As & $8,70 / 13,82$ & 9,55 & 10,03 & $12,60 / 10,34$ & 10,49 & 11.03 \\
\hline Semis & $4,82 / 6,41$ & 4,54 & 5,52 & & & 3,92 \\
\hline Cuadrante & & 2,62 & 2,64 & & & 2,66 \\
\hline
\end{tabular}

Figura 19. Comparativa de metrología entre colonias augusteas.

ases y semises, aportan un nuevo numerario a la colonia de los valores más utilizados a lo largo de las doce emisiones cívicas. Se proclama la vinculación de la propia ciudad a Tiberio, repitiendo tipos ya empleados con Augusto ${ }^{39}$.

Dupondio (RPC 41; DCyP, 127, 12 43).- De los treinta y tres ejemplares recopilados extraemos una media de 23,91 g y una oscilación de 15,93 g obtenida de pesos entre 14,45-30,38. Parece que continúan produciéndose las monedas, en esta última serie tiberiana, con la misma escasa pericia y cuidado métrico que en anteriores momentos.

As (RPC 42-48; DCyP, 127, 1244-49).- Las 247 monedas que hemos atestiguado nos dan un peso medio en la acuñación de 10,80 g y una amplia oscilación de 12,36 g $(5,30-17,66)$, lo que continúa indicando una tendencia parecida a las anteriores series de ases producidos en sus respectivas producciones, para unas técnicas de fabricación de cospeles y una pericia de los operarios que hicieron estas monedas. El gráfico muestra una concentración destacada entre los 10 y 12 g coincidente con el peso medio de esta emisión. No contamos con hallazgos documentados de estas monedas por lo que no podemos conjeturar sobre su finalidad. Los análisis metalográficos de estos ases tiberianos han revelado que se sigue utilizando la misma aleación ternaria de época augústea; sin embargo, en estos bronces emeritenses se observa un incremento del \% de cobre, algo que sin duda esta en relación con la aplicación de la reforma monetaria implantada por Augusto ${ }^{40}$. Ahora el cobre y el hierro alcanzan cifras superiores con Tiberio a las

\footnotetext{
${ }^{39}$ Cebrián (2005)

${ }^{40}$ Parrado (1998) pp. 108, 189 y 191.
}

augústeas mientras el plomo y el estaño descienden. Además en línea general las series tiberianas presentan una mayor homogeneidad en la aleación.

Semis (RPC 49; DCyP, 127, 12ª5).- Las mitades acuñadas en la última emisión tienen las siguientes características: un peso medio de $6,15 \mathrm{~g}$ y unos valores extremos de 4,08-7,98 g (lo que representa una oscilación de 3,90 g). Estos pesos son parecidos a otras series de semises acuñados en Emerita Augusta. El correspondiente gráfico parece coincidir con el peso medio, aunque los pocos ejemplares constatados, ocho, no nos permiten precisar esta cuestión.

\section{METROLOGÍA COMPARADA EN COLONIAS AUGÚSTEAS HISPANAS: TRADUCTA, PATRICIA, PAX IULIA Y EBORA.}

En este segundo apartado analizamos los pesos de aquellas cecas coloniales en época de Augusto que presentan una vinculación más directa con Augusta Emerita por causas estilísticas, de status jurídico, cronológicas o geográficas. La sexta emisión emeritense, es decir, la primera de carácter provincial es la que mantiene mayor vinculación con otras cecas augústeas, ya que sus valores, imágenes y métrica coinciden con los de otros talleres que a continuación analizamos. Hemos seleccionado Pax Iulia y Ebora, en la Lusitania y Patricia y Traduc$t a$, en la Bética. Los pesos medios que vamos a comparar proceden del trabajo de A. Burnett, M. Amandry y P. P. Ripollès ${ }^{41}$. Hemos creído conveniente hacer un cua-

\footnotetext{
${ }^{41}$ Burnett, Amandry y Ripollès (1992).
} 
dro general comparativo, además de incluir uno específico en cada apartado de ceca:

\section{TRADUCTA}

Esta colonia, de cuya categoría en su estatuto jurídico presenta ciertas dudas ${ }^{42}$, acuña una segunda emisión de monedas con valores parangonables a duplos, unidades, mitades y cuartos romanos, coincidentes éstos con los acuñados en la capital de la Lusitania ${ }^{43}$. Además, no podemos precisar más la fecha de las monedas de Traducta ya que no aparece el título de Padre de la Patria que sí encontramos en las de la Mérida romana.

\begin{tabular}{|c|c|}
\hline EMERITA & $6^{\text {a }}$ serie \\
\hline Dupondio & 19,47 \\
\hline As & 11,03 \\
\hline Semis & 3,92 \\
\hline Cuadrante & 2,66 \\
\hline
\end{tabular}

Figura 20. Metrología de Emerita.

\begin{tabular}{|c|c|}
\hline TRADUCTA & $1^{\text {a }}$ serie \\
\hline Dupondio & 19,76 \\
\hline As & 9,55 \\
\hline Semis & 4,54 \\
\hline Cuadrante & 2,62 \\
\hline
\end{tabular}

Figura 21. Metrología de Traducta.

El paralelo más próximo en el tiempo, y en cuanto a sus denominaciones, es la sexta emisión de Emerita donde encontramos, en época de Augusto, los mismos valores en las dos cecas (duplos, unidades, medios y cuartos). Por ello creemos que es el momento productivo más oportuno para proceder a su comparación. Los duplos de las dos cecas presentan unos pesos, 19,76 g (Traducta) y 19,47 g (Emerita), prácticamente iguales en ambas (diferencia de 0,29 g). Sin embargo, las unidades presentan unos valores de 9,55 g y 11,03 g, con una diferencia superior al gramo, lo suficientemente signifi-

\footnotetext{
${ }^{42}$ Volk (1994).

${ }^{43}$ Chaves (1979) $156-161$ y 168-173, 1979 y 1981, pág. 992 y 33-71. RPC, 98-110.
}

cativa para poder entrever una variación de técnica entre ambos talleres. Las mitades responden a unos pesos medios de 4,54 g y 3,42 g respectivamente, es decir, poco más de un gramo de diferencia y por último, los cuartos que en Iulia Traducta tienen 2,62 g y en Emerita Augusta de 2,68 g, son prácticamente iguales. Por lo que respecta a la composición química S. Parrado nos indica que los ejemplares analizados del museo de Valladolid ${ }^{44}$ ofrecen una aleación ternaria cobre-plomoestaño en la que el cobre tiene la proporción mayoritaria. También resalta la autora la presencia de plomo que llega a ser del $35 \%$ de la aleación, concluyendo que este comportamiento es un hecho diferenciador de Traducta frente al resto de cecas hispanas augústeas.

\section{PATRICIA}

La capital de la provincia ulterior Baetica cuenta con la serie de valores más completa de la península ibérica, homologables a sestercios, dupondios, ases, semises y cuadrantes romanos augústeos ${ }^{45}$, paralelizables a las realizadas en Oriente $(R P C, 1462-1466)$ por la ceca de Achaea y conocida como "fleet coinage". Colonia Patricia comparte con Emerita ciertas características numismáticas (tipos: insignias legionarias, corona cívi-

\begin{tabular}{|c|c|}
\hline EMERITA & $6^{\text {a }}$ serie \\
\hline Dupondio & 19,47 \\
\hline As & 11,03 \\
\hline Semis & 3,92 \\
\hline Cuadrante & 2,66 \\
\hline
\end{tabular}

Figura 22. Metrología de Emerita.

\begin{tabular}{|c|c|}
\hline PATRICIA & $1^{\text {a }}$ serie \\
\hline Sestercio & 37,25 \\
\hline Dupondio & 19,44 \\
\hline As & 10,03 \\
\hline Semis & 5,52 \\
\hline Cuadrante & 2,64 \\
\hline
\end{tabular}

Figura 23. Metrología de Patricia.

\footnotetext{
${ }^{44}$ Parrado (1998) pp. 99-103.

${ }^{45}$ Volk (1994) pp. 451-454. Chaves (1979). Cebrián (1997) pp. 63-66.
} 
ca, instrumentos sacerdotales), históricas (capitales provinciales romanas), que hemos creído lo suficientemente interesantes como para comparar los pesos de la serie $6^{\mathrm{a}}$ emeritense a la única patriciense. De nuevo en los análisis de S. Parrado ${ }^{46}$ encontramos un incremento en los porcentajes de estaño, no existiendo asociaciones significativas entre los demás elementos utilizados (cobre y plomo).

La sexta emisión de Emerita se fecha post-12 a.C. para Patricia y 2 a.C. en Emerita. La de Patricia parece una emisión conmemorativa por su calidad y singularidad, y por ello el uso del sistema augústeo es lógico y similar al de las primeras emisiones de Emerita. No sabemos qué patrón hubiera elegido Patricia de seguir acuñando más adelante con temas ciudadanos. En la fígura 23 hemos incluido el sestercio Patriciense aunque no contamos con paralelos en Emerita, pero es a partir del dupondio donde vamos a proceder a una comparación entre las dos cecas. Los duplos de Patricia presentan un peso de 19,44 g, frente a los 19,47 de Emerita, con diferencia mínima entre ellos. Las unidades de la Córdoba romana presentan unos pesos de 10,03 g frente a los 11,03 g de la Mérida romana, es decir un gramo de diferencia; las mitades de ambas cecas presentan una diferencia superior al gramo $(5,52-3,92)$. Por último, los cuartos tienen unos valores: 2,64 y 2,68 g. Así pues las diferencias ponderales entre ellos son mínimas.

\section{PAX IVLIA}

Dentro de la Lusitania romana se encuentra la Colonia Pax Iulia, Beja, Portugal; que acuñó junto con Emerita y Ebora y presenta en sus reversos una figura femenina que podría ser interpretada como la Pax constitu-

\begin{tabular}{|c|c|}
\hline EMERITA & $6^{\mathrm{a}}$ serie \\
\hline Dupondio & 19,47 \\
\hline As & 11,03 \\
\hline Semis & 3,92 \\
\hline Cuadrante & 2,66 \\
\hline
\end{tabular}

Figura 24. Metrología de Emerita.

\begin{tabular}{|c|c|c|}
\hline PAX IVLIA & $1^{\text {a }}$ Emisión & $2^{\mathrm{a}}$ serie \\
\hline As & 12,60 & 10,34 \\
\hline
\end{tabular}

Figura 25. Metrología de Pax Iulia.

\footnotetext{
${ }^{46}$ Parrado (1998)pp. 88-92.
}

yendo un tipo parlante ciudadano ${ }^{47}$. La fecha de emisión de estas monedas es discutida y podría corresponder bien a la fundación de la colonia en el 30 a. C. o en el 19 a. C. coincidiendo con la visita de Augusto $^{48}$.

Pax Iulia cuenta con varias emisiones que permiten comparar sus pesos y además tiene, de época augústea, valores comunes al taller emeritense. Hemos elegido las dos emisiones de Pax Iulia y los ases de la quinta y sexta emeritenses para proceder a su comparación, ya que pensamos que las dos series de Pax Iulia guardan relación con dos momentos diferentes en función de la reforma augústea, tal y como ocurrió en Emerita, aunque contamos con fechas difíciles de precisar en ambas cecas. Los ases de la primera emisión de Pax Iulia presentan 12,60 y los de la quinta de Emerita 10,05 g; del mismo modo los de la $2^{\circ}$ emisión tienen 10,34 g y los de la sexta 11,03 g. Reflexionando sobre la variación en los pesos, todos tienen un umbral propio de la técnica de acuñación al marco, con la que se realizan los cospeles, que no ofrecen garantías de producir monedas con pesos exactos. Estamos ante una situación que podría ser parecida en ambos talleres y que podría generalizarse en las demás cecas que hemos elegido para ser comparadas con las producciones monetales de la Mérida romana, aunque contamos con pocos ejemplos que lo testimonien.

\section{EBORA}

La antigua Colonia Liberalitas Iulia Ebora acuñó en época augústea una emisión con dos valores

\begin{tabular}{|c|c|}
\hline EMERITA & $6^{\text {a }}$ serie \\
\hline Dupondio & 19,47 \\
\hline As & 11,03 \\
\hline Semis & 3,92 \\
\hline Cuadrante & 2,66 \\
\hline
\end{tabular}

Figura 26. Metrología de Emerita.

\begin{tabular}{|c|c|}
\hline EBORA & $1^{\text {a }}$ serie \\
\hline Dupondio & 19,75 \\
\hline As & 10,49 \\
\hline
\end{tabular}

Figura 27. Metrología de Ebora.

\footnotetext{
${ }^{47}$ Volk (1996) pp. 495-496. Faria (1995) pp. 143-153. RPC, 52-53.

${ }^{48}$ DCyP, Vol. II, p. 315.
} 
(duplos y unidades), con la fórmula PERMISSV CAESARIS AVGVSTI. Los tipos empleados, instrumentos sacerdotales y corona cívica, relacionan esta ceca, estilística e iconográficamente, con la de Patricia $^{49}$. Esta emisión eborense tiene como paralelo inmediato la sexta emisión de Emerita, por cronología fundamentalmente, Ebora 12 a. C. y Emerita 2 a. C., con unos dupondios y ases de 19,47 y 11,03 g respectivamente, pesos éstos muy próximos a los de Ebora.

\section{ESTUDIO DE LA COMPOSICIÓN METÁLICA}

Lo ideal habría sido poder adjuntar a este estudio unos analísis sistemáticos de las aleaciones utilizadas hasta el momento. Sin embargo, sólo contamos con la documentación publicada por P. P. Ripollès y J. M. Abascal para las diferentes cecas republicanas de la península ibérica de donde se deduce una cierta heterogeneidad del contenido metálico, tanto en las diferentes cecas en sí, como incluso dentro de una misma serie ${ }^{50}$. Estos mismos autores observan que para las cecas republicanas los metales preponderantes son cobre, plomo y estaño. Su análisis continúa con el contraste de las aleaciones utilizadas en época imperial, cuyo panorama parece más claro, en los análisis utilizados por P. P. Ripollès en el $R P C$, concluyendo que se siguen utilizando los mismos metales que en el periodo republicano, a pesar de la nueva legislación del 23 a. C. de Augusto, donde se introducen nuevas aleaciones en la moneda oficial, especialmente el oricalco. Este cambio compositivo auspiciado por Augusto, que consiste en el uso del oricalco que valía el doble que el bronce, no da muestras de existencia real hasta época de Tiberio. El uso del oricalco (cobre+zinc) tiene un gran interés, ya que no sólo presupone la disponibilidad de cobre refinado, sino que además implica conocimientos técnicos complicados, pues los altos porcentajes de zinc encontrados en las monedas sólo se consiguen mediante el método de la cementación. También descarta el autor que nos encontremos con metales reciclados a partir de objetos o monedas imperiales romanas. S. Parrado realizó análisis de unas cuarenta monedas emeritenses, tanto de época augústea como tiberiana. En su estudio se destaca la diferencia de variabilidad en las aleaciones entre los dos emperadores, siendo menor en las de Tiberio, esto se argumenta en la correlación entre el cobre y el plomo, elevada en

\footnotetext{
${ }^{49}$ Vives (1926) T. IV, 114; Chaves (1979) pp. 33-34; Cebrián (1999), pp. 287-288.

${ }^{50}$ Ripollès (1995) pp. 131-155.
}

la moneda augústea, frente al porcentaje de cobre-estaño de las tiberianas ${ }^{51}$.

Además contamos con otras pequeñas muestras analizadas que todavía se encuentran en curso de publicación. Los análisis sobre los que vamos a basar nuestro trabajo son los recopilados por B. Bouyon, G. Depeyrot y J. L. Desnier anteriormente citados en nota, a los que unimos la información de tres ejemplares: un as (RPC, 42) de Astorga con una composición bimetálica de cobre $(43,52 \%)$ y estaño $(42,77 \%)$, es decir de bronce binario y dos ases (RIC $1^{2}$ p. $42, n^{\circ} 11$; RPC, 6) conteniendo respectivamente, el primero, una composición monometálica de cobre $(86,94 \%)$ y trazas de plomo y estaño y el segundo de composición similar con un $82,01 \%$ de cobre y $14,29 \%$ de estaño.

Una vez examinados los escasos porcentajes antes citados, nos encontramos con que la ceca romana de Mérida va a utilizar el cobre como principal componente de sus emisiones, tanto en época augústea como tiberiana, alcanzando porcentajes del noventa por ciento de su composición, siendo el ejemplar de Astorga una excepción. Por lo tanto, podemos ver cómo la utilización de un sólo metal preponderante, el cobre, la desmarca de otras cecas, cuyas monedas del mismo periodo han sido analizadas en Hispania por P. P. Ripollès y testimonian el empleo de oricalco en dupondios y sestercios en época tiberiana en Romula, Ilici y Caesaraugusta ${ }^{52}$. Para ésta última, además, confirma que la progresión continuó en el periodo de Calígula, siendo ya prácticamente utilizado en la totalidad de la producción. El cobre, sin embargo, se utilizó para ases, como en Emerita, aunque parece que, a tenor de los análisis, el cobre en la ceca emeritense va a acaparar todos los valores, uso éste que nos desvela las disponibilidades metálicas de la ceca lusitana que debió de abastecerse de él por cuestiones de economía, a través de las conocidas y próximas minas de Cerro Muriano, ricas en este mineral (Mela 2, 86; Plin $\mathrm{NH} 3$, 30; Est, 3, 2, 9) ${ }^{53}$.

La composición de la moneda de Emerita parece seguir los patrones que se vienen corroborando en los objetos metálicos encontrados en esa zona, entre ellos destacamos los ponderales de Cancho Roano de la segunda mitad del siglo V a. C., donde es el cobre el material aleado principalmente con estaño y plomo, según estudio de M. P. García-Bellido ${ }^{54}$.

\footnotetext{
${ }^{51}$ Parrado (1988) p. 104 y ss. Burnett, Amandry y Ripollè (1992). Parrado (1994) 107-118. Cope, King y Clay (1997) pp. 1-66. Bouyon, Depeyrot y Desnier (2000) p 119. Además de tres monedas emeritenses inéditas cedidas por C. Blázquez y A. Morillo a los que agradecemos esta gentileza, Proyecto PB 980656-C02-01, dirigido por la doctora M. P. García-Bellido.

52 RPC 73-74, 194 y 317-319 respectivamente.

53 Domergue (1990) p. 9.

${ }^{54}$ García-Bellido (2003) pp. 127-155.
} 


\section{CONCLUSIONES}

Son varias las reflexiones que pueden hacerse al elaborar y ordenar los pesos de las doce emisiones emeritenses. Por ello merece la pena tratar de ordenarlas como conclusión de las líneas precedentes:

I.- La comparación entre los pesos de todas las emisiones emeritenses muestra un mayor cuidado y control metrológico en la primera y la segunda emisión, debido a que se trata de moneda imperial, fabricada en el taller imperial de Emerita. El hecho de que se acuñara plata, máximo valor intrínseco de las monedas, ayudó a mantener una mayor regularidad posiblemente en relación con el pago al ejército y a los eméritos pagos efectuados incluso ya en otras provincias. Esta función de la primera moneda emeritense se corrobora con los hallazgos encontrados en los campamentos del limes germano, que justificarían el empleo de esta moneda por las tropas, portadoras de moneda imperial emeritense desde Hispania a Germania, tanto en los bolsillos de los soldados como en la propia caja militar ${ }^{55}$. La misma regularidad se observa en el bronce, también imperial, de la segunda emisión, la única que emite además los dupondios en oricalco siguiendo la normativa augústea.

II.- Para conocer la causa de esta regularidad es importante estudiar las diferentes técnicas utilizadas para la realización de cospeles y que van a repercutir en los pesos de las monedas. Para las series de plata es la técnica de cortado en barra la elegida por su mayor precisión, además del posterior pesado y cercenado del metal hasta adaptarse al patrón establecido. Las monedas de bronce que abarcan once de las doce series emitidas, emplean en la fabricación de sus cospeles la técnica de cortado en barra, junto con la de fundición en rosario, ya que testimoniamos en monedas de la misma denominación y serie, ambas técnicas. Es indudable que esta última técnica es mucho menos precisa que la anterior.

III.- En época tiberiana se comprueban nuevos avances técnicos. La mayoría de los cospeles de bronce se fabrican ahora por medio de cortado de barras y no por fundición en rosario, lo que influye notablemente en una mejor calidad de la acuñación y en unos pesos más regulares.

IV.- El metal empleado en Emerita es predominantemente el cobre. Se diferencia de los empleados por otras cecas, donde se testimonia la introducción paulatina del oricalco. Como hemos visto, sólo la serie imperial utiliza esta aleación. El uso exclusivo de cobre persistirá en época tiberiana y pone de manifiesto la dependencia metálica de la ceca con respecto a las ricas minas de Sierra Morena

${ }^{55}$ García-Bellido (2003) pp. 78-79. occidental, las más próximas a la ciudad, aunque hay que tener en cuenta la escasez de análisis realizados por ahora, que ocasiona una carencia importante de documentación.

V.- En la emisión que hemos clasificado como quinta, se utiliza un patrón metrológico que responde a unidades de trece gramos, similar al usado en época repúblicana en la bética y, aunque responde a series acuñadas posteriormente a las de P. Carisio, sigue utilizando el patrón local. Podemos hablar de la supervivencia de patrones métricos pre-augústeos en las acuñaciones ya coloniales emeritenses junto a pesos post-reforma. Ello parece indicar una diferencia en la administración imperial y colonial de la ciudad. Es evidente que la moneda emitida para asuntos imperiales, en este caso todos ellos en relación con el ejército y se plegó a una normativa imperial y pasó por controles de factura más rígidos y centralizados que los de la nueva colonia. Estos se ajustaron más a las normas y costumbres locales, tanto en la factura como en la metrología de la moneda. Sólo pues, con P. Carisius primero y con Tiberio más tarde, podremos comprobar una auténtica inserción de las emisiones monetarias de Emerita en una normativa imperial. Este planteamiento numismático puede hoy adecuarse muy bien a los nuevos criterios sobre el desarrollo urbanístico de la ciudad de Emerita y su territorio, que parece iniciarse más en tiempos de Tiberio que en los de Augusto, como creíamos ${ }^{56}$.

VI.- La comparación de la metrología monetal emeritense con la utilizada en Ebora, Pax Iulia, Patricia y Traducta permite comprobar que la metrología augústea que hemos visto en Emerita en las dos primeras series imperiales y a partir de la $5^{\mathrm{a}}$ y $6^{\mathrm{a}}$ provinciales se usó efectivamente en todas estas otras cecas. Las tres primeras parecen haber acuñado en el primer periodo augústeo c. 12 a. C. Traducta más bien en el segundo, post 2 a. C. La mayor dificultad estriba en que ellas acuñan sólo una o dos emisiones lo que no ha permitido un seguimiento completo como hemos hecho en Emerita, comprobando que aunque la ceca se inaugura con acuñaciones que sigue la reforma augústea, las posteriores emisiones de nuevo se hacen eco del patrón republicano, para volver al augústeo tras el año 2 a. C.

\section{BIBLIOGRAFÍA}

AMANDRY, M. (1986) "La genèse de la réforme monétaire augustéenne en Occident", Cercle d'Études Numismatiques 23-2, pp. 21-33.

BLÁZQUEZ, C. (1992) La dispersión de las monedas de Augusta Emerita, Mérida. - (2002) circulación monetaria en el área occidental de la península ibérica. Montagnac.

\footnotetext{
${ }^{56}$ Mateos (2001).
} 
BOUYON, B. DEPEYROT. DESNIER, J. L. (2000) Systèmes et technologie des monnaies de bronze, Wetteren.

BMC: GRUEBER, H. A. (1910) Coins of the Roman Republic in the British Museum (3 Vols.), London.

BURNETT, A., AMANDRY, M., RIPOLLÈS, P. P. (1998, 2e édition) Roman Provincial coinage, London/Paris.

CEBRIÁN, M. A. (1997) “Aportación al estudio de los prototipos iconográficos en las acuñaciones locales patricienses", Antiquitas 8, pp. 63-66.

- (2005) "La iconografía de las monedas de Colonia Augusta Emerita", Actas XIII Congreso Internacional de Numismática, Tomo I, pp. 835-838.

CHAVES, F. (1976) "Las monedas de Acci”, Numisma 138-143, pp. 141-158.

- (1979) La Córdoba hispano-romana y sus monedas, Córdoba.

- (1979) "Las cecas hispano-romanas de Ebora Iulia Traducta y Colonia Romula (I y II)", Numisma, pp. 156-161 y 168-173, 1979.

COLLANTES, E. (1989) "Conjeturas sobre metrología ibérica”, Numisma 204-221, pp. 47 y ss.

COPE, L. H. KING, C. E. CLAY, T. (1997) "Cope's analyses", Metal analyses Roman Coins, 120, pp. 1-66.

DCYP: GARCÍA-BELLIDO, M. P. Y BLÁZQUEZ, C. (2001) Diccionario de cecas y pueblos Hispánicos, 2 vols, CSIC, Madrid.

DOMERGUE, C. (1990) Les mines de la Péninsule Ibérique dans l'Antiquité romaine, Roma.

FARIA, A. M. (1995) "Moedas da época romana cunhadas em território actualmente português", Anejos de AEspA XIV, pp. 143.153.

GARCÍA-BELLIDO, Ma ${ }^{a}$. P. (1992) "Problemas técnicos de la fabricación de moneda en la Antigüedad", Numisma XXXII, Madrid, pp. 9-50.
- (2003) "Los ponderales y sus funciones económica y religiosa", en S. Celestino (ed.) Cancho Roano IX, Los materiales Arqueológicos II, Mérida, pp. 127-155.

- (2003) "La historia de la Colonia Lépida-Celsa según sus documentos numismáticos: su ceca imperial, AEspA 76, 273-290.

- (2004) Las legiones hispánicas en Germania, Anejos de Gladius 6, CSIC, Madrid, pp. 211, 280-282.

- (Coord.) (2006) Los campamentos romanos en Hispania (27 a. C. - 192 d. C.). El abastecimiento de moneda. 2 vols. CSIC. Anejos de Gladius 9, Madrid.

HOWGEGO, C. (1982) "Coinage and Military Finance: the Imperial Bronze Coinage of Augustan East", Numismatic Chronicle, pp. 2-7.

LLORENS, M. M. (1987) La ceca de Ilici, Valencia.

MATEOS, P. (2001) "Augusta Emerita. La investigación arqueológica en una ciudad de época romana", AEspA 74, pp. 183-208.

PARRADO, M. S. (1994) “Análisis metalográfico en el monetario del museo de Zamora", Actas IX CNN, Elche, pp. 107-118.

- (1998) Composición y circulación de la moneda hispano-romana en la meseta Norte, Valladolid.

RIPOLLÈS, P. P. (1997) "Augusto: las cecas hispanas", La Moneda en temps d'August", Barcelona,

RIC I, $2^{\mathrm{a}}=$ SUTHERLAND, C. H. V. (1984) The Roman Imperial Coinage, ed. Rev., London.

SUTHERLAND, C. H. V. (1976) The Emperor and the Coinage, London.

VIVES, A. (1926) La moneda Hispánica, Madrid.

VOLK, T. (1997) "Hispania and the gold and silver coinage of Augusto", en La moneda en temps d'August, Barcelona, pp. 59-90.

Recibido el 15-07-05

Aceptado el 15-03-06 